\title{
A interação entre Josef Albers e Augusto de Campos
}

\section{The interaction between Josef Albers and of Augusto de Campos}

\author{
Dirce Waltrick do Amarante \\ Universidade Federal de Santa Catarina, Florianópolis, Santa Catarina, Brasil \\ Sérgio Medeiros \\ Universidade Federal de Santa Catarina, Florianópolis, Santa Catarina, Brasil
}

Resumo: Um breve poema visual de Augusto de Campos que é uma tradução de Maiakóvski dialoga com a monumental série Homenagem ao quadrado, do artista plástico Josef Albers, inspirada, em parte, nas pirâmides e na paisagem mexicanas.

Palavras-chave: Augusto de Campos; Josef Albers; Poesia visual; Abstracionismo geométrico

Abstract: A brief visual poem by Augusto de Campos - which is a translation of Mayakovsky - dialogues with the monumental series Homage to the Square by artist Josef Albers, inspired in part by the pyramids and the Mexican landscape.

Keywords: Augusto de Campos; Josef Albers; Visual poetry; Geometric abstractionism 
No "plano-piloto para poesia concreta", publicado originalmente em 1958, na revista noigandres, e assinado por Augusto de Campos, Décio Pignatari e Haroldo de Campos, lê-se:

\footnotetext{
poesia concreta: tensão de palavras-coisas no espaço tempo. estrutura dinâmica: multiplicidade de movimentos concomitantes. também na música por definição, uma arte do tempo - intervém o espaço (webern e seus seguidores: boulez e stockhausen; música concreta e eletrônica); nas artes visuais - espaciais, por definição - intervém o tempo (mondrian e a série boogie-woogie; max bill; albers e a ambivalência perceptiva; arte concreta, em geral). (1975, p. 156.)
}

Destacaremos, dessa citação que associa a arte da palavra à música e às artes plásticas, apenas a referência à "ambivalência perceptiva" que acompanha a menção ao nome do artista e professor Josef Albers, que analisou o uso e a percepção das cores na arte. Para esse professor e artista, a forma e a cor eram cruciais e sua interação substituía, na manifestação artística, a expressão pessoal como representação da vontade e da personalidade.

Começaremos fazendo um breve relato da carreira de Albers (1888-1976). Ele foi professor, pintor, escritor e teórico da cor. Entre suas obras destaca-se Homage to Square, ou Homenagem ao quadrado, uma vasta série de quadros realizada entre 1930 e 1976, sobre a qual voltaremos a falar. Estudou e lecionou na Bauhaus (Weimer e Dassau, na Alemanha), antes de radicar-se definitivamente na América (ensinou, primeiro, na Black Mountain College, na Carolina do Sul, e depois na Yale University, em New Haven), juntamente com sua esposa e artista têxtil Anni Albers, como uma reação à ascensão de Hitler ao poder. O desenvolvimento de seu trabalho e de suas ideias na América deve muito às suas frequentes viagens ao México, país que ele passou a considerar a "terra prometida da abstração", devotando-se ao estudo dos monumentos pré-colombianos, como as pirâmides ameríndias. Numa carta de 1936 a Kandiski, ele afirmou cheio de entusiasmo: “O México é verdadeiramente a terra prometida da arte abstrata, pois aqui ela já tem mais de mil anos" $(2018$, p. 23).

Contudo, o México era para ele também a terra da cor, uma cor pré-colombiana e também contemporânea, que podia encontrar visitando a Mesoamérica como um todo e 
cuja ênfase lhe parecera inédita. Como já foi tantas vezes enfatizado por críticos e estudiosos, seu desenvolvimento artístico foi inseparável da pesquisa e do ensino, e por conta disso ele se tornou, ao lado da esposa, um grande colecionador de arte précolombiana.

No seu influente ensaio A interação da cor, publicado originalmente em 1963, que resume a sua visão sobre a importância das cores nas artes, Albers afirma, já na introdução: "Para utilizar a cor de maneira eficaz, é preciso reconhecer que a cor sempre engana” (2016, p. 3.) Assim, para esse artista-educador, uma mesma cor provoca numerosas leituras, e é justamente a isso que parece aludir o "plano-piloto para poesia concreta", embora os poetas brasileiros tenham escrito o texto antes de Albers publicar o referido livro. Porém, seus princípios estéticos, assim como os de Max Bill, outro importante professor (formando na Bauhaus e depois atuante na Escola Superior de Desenho, em Ulm), citado no “plano-piloto”, já eram conhecidos no Brasil.

É preciso lembrar que Max Bill se encontrou com Albers no Peru, em 1953, e na ocasião o convidou a voltar para a Alemanha, parar ser professor convidado na recémfundada Hochschule für Gestaltung em Ulm. Antes disso, em 1951, Max Bill havia exposto na I Bienal do Museu de Arte Moderna de São Paulo, onde obteve o prêmio internacional de escultura. $\mathrm{O}$ artista fez conferências sobre arte concreta e educação artística, em 1952, em nosso país, e sempre dialogou com Albers, de modo que os princípios estéticos compartilhados por ambos passaram a circular entre artistas brasileiros, como Lygia Clark e Hélio Oiticica, entre tantos outros.

Aqui é preciso mencionar uma terceira figura de proa, o poeta suíço-boliviano Eugen Gomringer, que se dedicava a fazer visual e era secretário de Max Bill, além de também ensinar na Escola Superior da Forma, na Alemanha. O poeta Décio Pigntari manteve contato estreito com ele a partir de 1954, conforme ele mesmo conta num depoimento de 1957, em que destaca os pontos em comum entre os poetas concretos brasileiros e os concretos europeus, num momento em que a denominação "poesia concreta" ainda não era adotada por ambos os grupos:

De resto, é bom notar, de passagem, que a estagnação da poesia é um fenômeno de todos os países na hora presente: somente na Alemanha consegui encontrar um reduzido grupo de poetas, ligados à revista Spirale e chefiados pelo suíçoboliviano Eugen Gomringer, empenhados na "poesia-sem-verso", a que tinham recém-chegado a partindo de pontos comuns aos nossos (Un Coup de Dés, de Mallarmé, Cummings etc.) - pontos esses que os poetas concretos 
brasileiros - pelos menos os de São Paulo - tinham conseguido estabelecer no decorrer de oito anos de trabalho (1975, p. 58).

A fonte utilizada pelos poetas brasileiros no seu manifesto poético não foi, então, o livro $A$ interação da cor, embora o conteúdo dele fosse conhecido. Hoje clássica, essa obra de Albers resume sua concepção do tema e por essa razão é a fonte de que nos valeremos. Seu objetivo é desenvolver a percepção das cores e destacar, portanto, as ambivalências citadas pelos poetas concretas, conceito que pode ter chagado ao Brasil por fontes indiretas.

Um dado importante, no ensino de Albers, era criar experiências (exemplificadas no livro) que permitissem aos alunos (a prática precedia a teoria) sentir as relações que se estabelecem entre as cores. O objetivo era ensinar que, "na percepção visual, há uma discrepância entre o fato físico e o efeito psíquico" (2016, p. 4), destacando a interdependência da cor com a forma e a localização, a quantidade, a qualidade e o realce.

No "plano-piloto para poesia-concreta", os autores enfatizam, no trecho citado, a música e as artes visuais. Alberts também propõe um paralelo entre as duas artes, afirmando: "Somos capazes de ouvir um som isolado, mas quase nunca (isto é, sem mecanismos especiais) de ver uma cor isolada, separada e sem relação com as outras" (Op. cit., p. 9). Temos aqui, ao contrário dos sons musicais, as cores se apresentando num fluxo contínuo.

Num artigo publicado originalmente no Suplemento Dominical do Jornal do Brasil, o crítico e poeta Ferreira Gullar, que colaborou nesse jornal escrevendo sobre arte contemporânea entre março de 1959 e outubro de 1960, num período de afirmação do movimento neoconcreto carioca (uma "dissidência" do concretismo paulista), apresenta assim a noção de quadrado (figura geométrica cara a paulistas e cariocas) e as mútuas influências dos elementos cromáticos inseridos nele:

O que preocupa o artista é a diferença entre fato físico e efeito psíquico.

O quadrado é 'humano': ele é uma construção intelectual que quase nunca ocorre na natureza.

O que é necessário é menos expressão e mais visualização.

Se você ativa o vermelho, ele vai mudando de identidade, torna-se verde ou outra cor qualquer.

Toda coisa tem forma e toda forma tem significação.

A medida da arte é a proporção entre esforço e o efeito (1985, p. 222). 
Ao definir o neoconcretismo como uma tomada de consciência autônoma dos problemas da arte contemporânea, Gullar também afirma que as ideias concretistas vieram de Ulm através de Buenos Aires, lançando luz sobre as origens de certas informações sobre o movimento construtivista europeu (no qual naturalmente se insere Albers) entre os poetas e artistas plásticos de São Paulo nos anos 1950.

O que gostaríamos de discutir, neste artigo, é a utilização das cores na poesia visual brasileira, que, conforme se sabe, se apoiou em outras artes, daí o diálogo dos concretos paulistas com Albers. Vamos nos limitar a uns poucos exemplos oriundos da obra de Augusto de Campos, considerando tanto o período da estética propriamente concreta (que utiliza palavras e não imagens), como o período posterior, a partir de "Popcretos", do início dos anos 1960, que inclui imagens e fotos. Os novos poemas “combinam imagens e ícones que o poeta extrai do 'aleatório do ready-made, do maior parque gráfico e tipográfico do mundo: os jornais e as revistas"”, como lemos em Poesia concreta brasileira (2005, p. 108), do crítico argentino Gonzalo Aguilar. Ele prossegue: 'Nos Popcretos (sic), o detrito não é semântico, mas sim objetual, um ‘júbilo do objeto' - para usar uma expressão de Haroldo de Campos - que desestabiliza os limites do poema e sua autonomia, mas principalmente ao critério da homogeneidade" (Op. cit., p. 109), critério que remete à fase anterior do poeta, a propriamente concreta dos anos 1950. O impulso construtivo passa então a conviver com o elemento anárquico: "A partir da antropofagia, a poesia concreta inclui o seu outro (caos, destruição, anarquia) e, assim, prepara a transformação dos critérios que estavam em suas origens” (Op. cit., p. 109).

Nossa proposta é ler agora "sol de maiakóvski”, um poema de Augusto de Campos publicado no livro Despoesia, de 1994, tomando como referência a ambiguidade das cores na obra de Albers, especialmente ma série dedicada ao quadrado. Ao comentar esse poema a partir do conceito de "intradução", Gonzalo Aguilar afirma:

Os procedimentos básicos das intraduções são: o recorte de unidades arbitrárias (não-determinadas pelo marco original), o uso de critérios visuais, a interpretação mediante tipografias, a atribuição de novo título e o pastiche. Por exemplo, "sol de maiakóvski" toma uma inscrição que o poeta soviético faz em uma porta, dois versos de cantores de massa (Caetano Veloso e Roberto Carlos), um título posto pelo autor e uma disposição dos tipos em torno da palavra 'tudo' sublinhada” (2005, p. 282). 
Os versos dizem: "brilhar para sempre / brilhar como um farol / brilhar com brilho eterno / gente é pra brilhar / que tudo mais / vá pro inferno / este / é o meu slogan / e o do sol". Eles estão inseridos num quadrado, no qual se percebem círculos (sóis, um dentro do outro) que se expandem, a partir de um centro pálido. Como afirmou Aguilar, a palavra "tudo" está sublinhada, na medida em que ocupa sozinha o sol mais interior e aparece rodeada, de um lado, pela palavra "que" e, do outro, pela palavra "mais", que funcionam como raios, se considerarmos que, dentro do quadrado, estão os "sóis" (trata-se do fundo do poema). Em outras palavras, o sol nasce e vai aumentando, até "romper" (ele é um círculo em expansão) as margens da quadrícula, forma típica da estética concreta.

Na versão reproduzida por Aguilar em seu livro, o sol branco é sucedido por um sol maior amarelo-pálido (o fundo agora tem cor), ou seja, os sóis vão recebendo tons mais fortes à medida que aumenta sua circunferência, enquanto que as letras dispostas sobre eles são todas na cor marrom. Contudo, na versão do mesmo poema que consta do livro Despoesia, o sol central é cinza claro, e os outros sóis, também cinzentos, vão ficando cada mais intensificados, de modo que a cor cinza chega finalmente ao preto. Nessa versão cinzenta, as letras dos versos são brancas e a palavra tudo, no centro, se diferencia de todas as demais porque lhe foi dado um contorno preto que a projeta para a frente ("impressão em relevo"), fazendo-a mais escultural (concreta, como um objeto) do que as outras. A palavra exibe a sua aura...

Trata-se de uma das versões do poema, que aparentemente não teria uma versão “oficial". Desse modo, a versão amarela reproduzida por Aguilar não seria "espúria"; além disso, ela está disponível na internet, assim como outros poemas do autor, ilustrando a possibilidade de o poema receber vários tratamentos de cor. Numa das imagens divulgadas online, esse poema aparece emoldurado como um quadro na parede. Nesse sentido, ele poderia, sim, ser comparado aos quadrados de Albers,

Mas a comparação poderia ir além: os sóis em expansão que criam uma sequência de formas circulares se parecem com os quadrados também em expansão na obra de Albers, que utilizou, em algumas versões da sua homenagem ao quadrado, vários tons de cinza e, em outras, vários tons de amarelo. O quadrado de Albers poderia estar, como uma possibilidade, por trás dos sóis de Maiakóvski, arranjados, como sabemos, sobre uma quadrícula.

Sobre a presença de Albers na poesia de Augusto de Campos, o crítico argentino, depois de falar de maneira geral sobre a importância do tamanho, da posição e das cores das letras usadas pelo poeta, não apenas cita Albers, como também fala em poema- 
quadro, conceito ao qual o poema que estamos comentando parece corresponder plenamente:

\begin{abstract}
Em 1986, Augusto de Campos publicou Expoemas (1980-1985), serigrafias de seus poemas realizadas em colaboração com Omar Guedes. Essas serigrafias, por seu grande tamanho $(40$ X $36 \mathrm{~cm})$, podem ser penduradas como se fossem quadros. Nelas, o uso das cores lembra Poetamenos (sic), embora nas serigrafias os tipos variem e o trabalho de contraste já não se faça entre as letras e sim entre as letras e o fundo. A utilização material das cores responde à arte concreta, ao uso de contrastes e vibração [...]. O trabalho, nesta série, é predominantemente visual e utiliza as teorias das cores como a de Josef Albers (tão influente no concretismo dos anos 1950), mas não para fazer poemas pictóricos e sim para deslocar esses efeitos para as relações entre as palavras (2005, p. 225).
\end{abstract}

"Poetamenos" consta da Poesia 1949-1979, de Augusto de Campos.

Longe de ilustrar simplesmente a teoria de que as cores se modificam umas às outras, a ponto de perderem sua identidade e se tornarem irreconhecíveis (o verde se torna azul), a obra de Albers - sobretudo a Homenagem ao quadrado, na qual trabalhou por 25 anos - induz no fruidor sensações que ativam tanto a visão como o corpo todo, ao proporlhe uma experiência com formas e cores que se expandem (e/ou se recolhem) no plano físico e psíquico. Quem se coloca diante do quadro, poderá perceber os quadrados coloridos sobrepostos (um dentro do outro) saltando para fora da parede ou, ao contrário, afundando-se nela. Por conta disso, o fruidor se sentirá (e a sua posição diante do quadro será crucial) ora no fundo de uma pirâmide, ora no topo dela.

A palavra "pirâmide", usada por nós para descrever a perspectiva a partir da qual se observa a série de quadrados sobrepostos, merece uma explicação à parte e alude ao encontro de Albers com os monumentos pré-colombianos, ao longo de vários anos. As ruínas monumentais, sobretudo as pirâmides ameríndias, estão estreitamente relacionadas à noção de quadrados de diferentes dimensões que se sobrepõem uns aos outros (estabelecem-se relações entre formas geométricas pictóricas e arquitetônicas), de modo que compartilham as mesmas propriedades visuais dos quadros de Albers. Pode-se afirmar que o quadro de Albes e a pirâmide indígena sugerem/formam um sólido que, quando visto do chão (perspectiva potencial, no caso da obra de Albers), é um V invertido, mas que, visto do alto, seria apenas um quadrado que contivesse outros quadrados menores. 
Albers, que explorou as pirâmides de dentro e de fora, e de ângulos diversos, teria tido uma visão diferenciada delas, englobando também sua exploração aérea. Resumidamente, poderíamos afirmar que os padrões geométricos da série Homenagem ao quadrado já estão nas pirâmides milenares visitadas pelo pintor alemão, assim como as cores vibrantes da passagem mexicana (as paredes das casas, em particular, bastante coloridas, foram exploradas por Albers na série Variant/Adobe) podem ser reencontradas na sua palheta. Essa constatação confunde definitivamente as noções de antigo e moderno, ao mesmo tempo que comprova a vitalidade da arte abstrata ao longo de milênios, pois ela definitivamente não nasceu na Alemanha da Bauhaus ou na Rússia de Kandinski e Malévitch.

A esse respeito, Lauren Hinkson opina, com admiração, que "Albers criou longas sequências de trabalhos relacionados que revelam como até mesmo padrões geométricos básicos e uma gama limitada de cores podem criar uma complexidade visual que excede a capacidade que o espectador tem de percebê-la" (2020, p. 18). O artista minimalista Donald Judd, num ensaio de 1991 citado no livro acima, já chamava a atenção para a conexão da obra geométrica de Albers com o México, afirmando que a Homenagem ao quadrado começa com a pintura das fachadas de casas no México, cujas janelas, portas e quinas são esboçadas por faixas de cor. Após afirmar que o México ofereceu ao artista alemão um laboratório para redefinir a arte moderna, o estudiosos Joaquín Barriendos conclui, completando o que dissera Judd, que a Homenagem ao quadrado retrata não apenas o aspecto externo de uma pirâmide mesoamericana, mas também a experiência de descer até o seu centro tectônico. E conclui que seus quadros de modo algum evocam simplesmente a forma de uma pirâmide vista de cima, pois, graças ao uso construtivo de cores, expõem os fundamentos espirituais da arquitetura pré-colombiana (Op. cit., p. 36).

Essa faceta da obra de Albers parece pouca discutido no Brasil, embora seja conhecida nos países vizinhos, como a Argentina, terra do pintor César Paternosto, que afirma: "A volumetria tectônica da antiga arquitetura mexicana exerceu sobre a obra de Josef uma influência considerável; ele se empenhou em traduzi-la na superfície plana da tela e numa série de "estruturas gráficas"” (2018, p. 67.)

Figura de referência para artistas visuais e poetas concretos brasileiros, Josef Albers de certa maneira levou o abstracionismo geométrico nacional (ainda que 
aparentemente de modo inconsciente, na maioria dos casos) a dialogar com a arte abstrata milenar das Américas, especialmente a mexicana e a peruana.

\section{Contribuição}

Dirce Waltrick do Amarante: Escrita - rascunho original, Escrita - análise e edição; Sérgio Medeiros: Escrita - rascunho original, Escrita - análise e edição.

\section{Referências}

AGUILAR, Gonzalo. Poesia concreta brasileira: as vanguardas na encruzilhada modernista. São Paulo: Edusp, 2005.

ALBERS, Josef. A interação da cor. São Paulo: WMF Martins Fontes, 2016.

CAMPOS, Augusto de; CAMPOS, Haroldo de; PIGNATARI, Décio. Teoria da poesia concreta: textos críticos e manifestos (1950-1960). São Paulo: Duas Cidades, 1975.

CAMPOS, Augusto de. Despoesia. São Paulo: Perspectiva, 1994.

CAMPOS, Augusto de. Poesia 1949-1979. São Paulo: Duas Cidades, 1979.

GULLAR, Ferreira. Etapas da Arte Contemporânea: do cubismo ao neoconcretismo. São Paulo: Nobel, 1985.

HINKSON, Laure (org). Josef Albers in Mexico. New York: Guggenheim Museum Publications, 2020.

LIESBROCK, Heinz (ed). Josef Albers: Interaction. Yale: Yale University Press, 2018.

COUTON, Pierre-Édouard (ed.). Géométries Sud: du Mexique à la Terre de Feu. Paris: Fundação Cartier, 2018.

Recebido em: 22 de setembro de 2021

Aceito em: 01 de dezembro de 2021

Publicado em dezembro de 2021

Dirce Waltrick do Amarante

E-mail: waltrickdoamarantedirce@gmail.com

ORCiD: https://orcid.org/0000-0002-5246-6844
Sérgio Medeiros

E-mail: medeirosrodriguessergio@gmail.com

ORCiD: https://orcid.org/0000-0003-4263-7942 